M. GÓMEZ, S. F. MEDINA
"Role of Microalloying Elements on the
Microstructure of Hot Rolled Steels"
International Journal of Materials Research,
Vol. $102(2011)$, Pages: $1197-1207$
ISSN: $1862-5282$


Manuel Gómez, Sebastián F. Medina

National Center for Metallurgical Research (CENIM-CSIC), Madrid, Spain

\section{Role of microalloying elements in the microstructure of hot rolled steels}

A comparative study of some of the most important effects of the diverse microalloying elements on austenite and ferrite microstructure of hot rolled microalloyed steels is carried out. The values of different aspects such as pinning and driving forces, size of precipitates, activation energies or diffusion coefficients are discussed. Titanium is the most effective element to control grain growth at high reheating temperatures and a weight $\mathrm{Ti} / \mathrm{N}$ ratio close to 2 is recommended. Aluminum can help to control grain growth at medium temperatures, but its addition to Ti steels can promote abnormal grain growth. Niobium is the most effective element to inhibit static recrystallization of austenite, due to the adequate precipitation temperature range at deformation temperatures and the strong pinning effect of $\mathrm{Nb}$ carbonitrides. Finally, the preferential nucleation of intragranular ferrite on particles such as vanadium carbonitrides enhances the ferrite grain refinement.

Keywords: Microalloyed steel; Thermomechanical processing; Recrystallization; Precipitation; Grain size. 


\section{Introduction}

The type and amount of microalloying elements dissolved in austenite have a considerable effect on grain growth, progress of recrystallization, and phase transformation [1-5]. However, the main reason for the presence of elements such as $\mathrm{Ti}, \mathrm{Nb}$ and $\mathrm{V}$ in microalloyed steels lies in their precipitation, and particularly in the interaction of particles of these elements and interstitials (C, $\mathrm{N})$ with austenite grain boundaries in motion. Whereas solutes hinder the advance of grain boundaries by means of a friction effect originated by the difference in their atomic radius compared with iron, precipitates cause a decrease in the effective grain boundary area and thus in the associated surface energy. The latter leads to an obstruction of grain boundary motion or a pinning effect which is much stronger than the solute drag. The stronger effect of precipitates compared to the solutes can be seen, for example, when the values of the activation energy for static recrystallization of austenite in the presence of strain-induced precipitates are compared to the lower values found when the microalloying elements are in solution. The value of the activation energy in the presence of solutes can be expressed for $\mathrm{Nb}$ and $\mathrm{V}$-microalloyed steels as [2]:

$$
\begin{gathered}
Q_{x}\left(\mathrm{~J} \cdot \mathrm{mol}^{-1}\right)=148636.8-71981.3[\% \mathrm{C}]+21180[\% \mathrm{Mn}]+56537.6[\% \mathrm{Si}]+ \\
121243.3[\% \mathrm{Mo}]+64469.6[\% \mathrm{~V}]+109731.9[\% \mathrm{Nb}]^{0.15}
\end{gathered}
$$

where each amount in brackets indicates the mass percentage of the element indicated. On the

other hand, the increase in activation energy due to the presence of precipitates in $\mathrm{V}$ and $\mathrm{Nb}$ microalloyed steels will be respectively [6]:

$$
\Delta Q_{\mathrm{x}}\left(\mathrm{J} \cdot \mathrm{mol}^{-1}\right)=1074 \cdot 10^{3} \cdot(\% \mathrm{~V} \% \mathrm{~N})^{0.223}
$$




$$
\Delta Q_{\mathrm{x}}\left(\mathrm{J} \cdot \mathrm{mol}^{-1}\right)=1577 \cdot 10^{3} \cdot\left(\% \mathrm{Nb} \% \mathrm{C}^{0.7} \% \mathrm{~N}^{0.2}\right)^{0.254}
$$

Zener [7] proposed that the driving pressure for grain growth due to the curvature of the boundary would be counteracted in particle-containing materials by a pinning pressure exerted by the particles situated at the boundary. Normal grain growth would be completely inhibited when the grain size reached a maximum, given by the critical radius $R_{\mathrm{c}}$ :

$$
R_{\mathrm{c}}=\frac{4}{3} \cdot \frac{r}{f}
$$

where $r$ is the radius of the pinning second-phase particles and $f$ their volume fraction.

This equation demonstrated for the first time that a decrease in the size of second phase particles and an increase in their volume fraction lead to grain refinement. This is crucial not only for microalloyed steels but also for aluminum alloys and many other materials of industrial interest. As proof of the value of Zener's equation, various authors have confirmed, completed or modified this equation for normal grain growth and have extended it to the case of abnormal growth [8]. All the interpretations of Eq. (4) can be adapted to a general expression:

$$
R_{\mathrm{c}}=K \frac{r}{f^{m}}
$$

where the adimensional constant $K$ and the exponent $m$ depend on the model considered. 
The different versions of Eq. (5) vary Zener's initial hypotheses, regarding the geometry of the zone of interaction between particle and grain boundary, the particle distribution, the relationship between boundary curvature and grain radius, and the original distribution of sizes [9-14].

To control the austenite grain size at high temperatures there must be a high proportion of fine particles and the solubility temperature $T_{\mathrm{s}}$ must be high enough, and it is also essential that the particles do not coarsen or coalesce at temperatures below $T_{\mathrm{s}}$ [15]. The amount of solute in the matrix will exert an important influence on precipitate coarsening and consequently on the ability to inhibit grain growth, both for simple additions and for steels with more than one type of microalloying element or precipitate.

The phenomenon of grain growth in the presence of precipitates of microalloying elements that exert a Zener-pinning effect has been simulated by several authors [16, 17]. One of the most interesting aspects of Zener's equation lies in its application to other annealing phenomena occurring in particle-containing materials besides grain growth, especially the static recrystallization of microalloyed steels. Many models on the inhibition of recrystallization by precipitates of microalloying elements have been presented [18, 19]. In summary, all these hypotheses start from the same idea, similar to that of Zener: there is a driving pressure (usually taken as a "force") for recrystallization $F_{\mathrm{R}}$ that comes from the stored energy of the deformation applied to the steel $[20,21]$, and an opposite pinning force $F_{\mathrm{P}}$ exerted by the precipitates that lessens the grain boundary surface energy. Depending on the net driving pressure $\left(F_{\mathrm{R}}-F_{\mathrm{P}}\right)$, recrystallization progresses or stops. 
The progress or blockage of the recrystallization and the control of grain growth have an effect on the grain size, grain elongation or dislocation density in the austenite during and at the end of thermomechanical processing, and this microstructure plays a crucial role in the microstructure after cooling. In this work, some of the most important effects of the type and amount of microalloying elements are presented and discussed in terms of the values of different aspects such as pinning and driving forces, size of precipitates, activation energies, diffusion coefficients or the level of austenite strengthening at the end of hot rolling.

\section{Experimental procedure}

Most of the steels studied in this work (Table 1) were manufactured by Electroslag Remelting (ESR) in a laboratory unit capable of producing $30 \mathrm{~kg}$ ingots. This technique avoids macrosegregation, both in alloying elements and impurities, and there is considerably less microsegregation; these effects being present in conventional ingots and continuous casting billets. The hot rolling simulations and the tests to calculate the recrystallized fraction were carried out in a computer-controlled hot torsion machine on specimens with a gauge length of 50 $\mathrm{mm}$ and diameter of $6 \mathrm{~mm}$, which were protected by an argon flow. The torsion magnitudes (torque and number of revolutions) were transformed into equivalent stress and strain according to Von Mises criterion [22]. The recrystallized fraction was determined using double deformation technique, in particular the method known as "back extrapolation" [23-25]. On the other hand, all the microstructural studies were done observing more than 20 fields on a longitudinal surface of 
the specimens at $2.65 \mathrm{~mm}$ from the axis. The austenite grain size $\left(D_{\gamma}\right)$ was determined by means of quenching and subsequent metallographic analysis applying ASTM standard E-112. Finally, the characteristics of the precipitates were determined by transmission electron microscopy (TEM) using the carbon extraction replica technique.

\section{Results about some of the most important effects of the addition of microalloying elements on the microstructure of steels}

The behavior during reheating at high temperature and hot deformation of steels with titanium as the unique nitride or carbide-forming microalloying element is substantially different to that of other microalloyed steels. The reason for this is that, whereas niobium or vanadium precipitates are dissolved at the reheating temperatures, titanium nitrides (TiN) have low solubility in austenite and their complete dissolution is not possible unless the reheating temperature is very high, close to the melting point of steels, or in some cases, depending on the chemical composition, at temperatures corresponding to the liquid state [26-28]. This characteristic makes Ti (in combination with N) an ideal element to control austenite grain size in processes involving the application of heat, for instance in forging applications or in the heat affected zone in welding [29]. For this reason, the addition of $\mathrm{Ti}$ is indispensable in structural steels with weldability requirements.

The TiN particles precipitated in the austenite (or more generally ( $\mathrm{Ti}, \mathrm{N}$ )-rich carbonitrides) are typically square-shaped or “cuboidal” [30-32], as those shown in Fig. 1. These particles exert a 
pinning effect on austenite grain boundaries in motion during reheating and help to control austenite grain growth. However, an increase in the titanium content in microalloyed steels does not necessarily mean that the grain will be always refined. Figure 2 shows the austenite grain size after reheating at $1300{ }^{\circ} \mathrm{C}$ measured in several steels with similar $\mathrm{C}$ content (near $0.1 \% \mathrm{C}$ ) but different Ti and $\mathrm{N}$ contents represented versus their weight $\mathrm{Ti} / \mathrm{N}$ ratio. It can be seen that $D_{\gamma}$ presents a minimum value for $\mathrm{Ti} / \mathrm{N}$ ratios near but lower than the stoichiometric value, i.e. the ratio of the molecular weights of $\mathrm{Ti}$ and $\mathrm{N}(47.87 / 14=3.42)[33,34]$.

Small precipitates grow by Oswald ripening according to Lifshitz, Slyozov and Wagner's expression [35], which accurately predicts precipitate growth as a function of the temperature and holding time. Considering an initial precipitate radius $\left(r_{0}\right)$, the average size $(r)$ of a particle after time $t$ will be [36]:

$$
r^{3}=r_{\mathrm{o}}^{3}+\frac{8 \gamma D V^{2} C}{9 R T} \cdot t
$$

where $\gamma=0.8 \mathrm{~J} \cdot \mathrm{m}^{-2}$ is the interaction energy between the precipitates and the iron matrix (austenite); $D=1.5 \cdot 10^{-5} \exp (-251000 / \mathrm{RT}) \mathrm{m}^{2} \mathrm{~s}^{-1}$ is the volume diffusion coefficient of titanium in austenite; $V=11.9 \cdot 10^{-6} \mathrm{~m}^{3} \mathrm{~mol}^{-1}$ is the mole volume of TiN; $C$ is the solute concentration in the matrix that is in equilibrium with a particle $\left(\mathrm{mol} \cdot \mathrm{m}^{-3}\right) ; R=8.3145 \mathrm{~J} \cdot \mathrm{mol}^{-1} \cdot \mathrm{K}^{-1}$ is the universal gas constant; $T$ is the temperature $(\mathrm{K})$ and $t$ is the time (s).

$\mathrm{Ti} / \mathrm{N}$ ratio is closely related to the amount of $\mathrm{Ti}$ in solution, i.e. with the term $C$ of the equation. Therefore, according to the above expression, Ti/N ratio and precipitate size are linked [37]. This 
can be better observed in Fig. 3, which shows the mean particle size for the steels studied as a function of $\mathrm{Ti} / \mathrm{N}$ ratio [33, 34]. This plot focuses on the population of small precipitates, i.e. the particles finer than $100 \mathrm{~nm}$, which represents about $50 \%$ of the total amount, although a certain fraction of the coarser TiN particles can be bigger than $1 \mu \mathrm{m}$ [33]. The size selected to separate the fine precipitates from the coarse precipitates was established bearing in mind that the pinning forces are very weak for precipitates larger than $100 \mathrm{~nm}$ [38]. Similar size criteria to label precipitates as “small” have been used elsewhere [39]. Particle size after reheating at $1300{ }^{\circ} \mathrm{C}$ clearly shows a minimum for Ti/N ratios lower than the stoichiometric and close to 2 . Consequently, pinning forces exerted by the TiN particles will be higher and the austenite grain growth at high temperatures will be better controlled for hypo-stoichiometric ratios close to 2, as Fig. 2 showed. It should be said that the Ti/N ratio is basically a technical parameter upon which the grain size considerably depends, but other variables can strongly influence $D_{\gamma}$. A small value of precipitated volume fraction associated to small $\mathrm{Ti}$ and $\mathrm{N}$ additions can lower the value of pinning forces and consequently induce a coarser austenite grain size. In contrast, Ti in solution with hyper-stoichiometric Ti/N ratios can help to control grain growth to some extent.

The $\mathrm{Ti} / \mathrm{N}$ ratio and the precipitation state associated to this parameter notably influence other phenomena occurring during thermomechanical processing of microalloyed steels. For example, a relationship between the precipitation state and the maximum strength of Ti microalloyed steels during hot deformation can be described and the precipitation state affects the value of the activation energy for deformation $Q_{\mathrm{d}}$ [40]. The increase of activation energy due to precipitation $\left(\Delta Q_{\mathrm{d}}\right)$ reaches a maximum when the $\mathrm{Ti} / \mathrm{N}$ ratio is between 1 and 2, as Fig. 4 shows. In other words, an increase in $\mathrm{Ti}$ content in microalloyed steels does not necessarily mean that the 
deformation strength also increases. The curve of Fig. 4 follows Eq. (7) [40] and the value of $Q_{\mathrm{d}}$ can be introduced in the Eq. (8) of the Zener-Hollomon parameter [41]:

$$
\begin{aligned}
& \Delta Q_{\mathrm{d}}\left(\mathrm{J} \cdot \mathrm{mol}^{-1}\right)=-7678\left(\ln \frac{\mathrm{Ti} \%}{\mathrm{~N} \%}\right)^{2}+3990\left(\ln \frac{\mathrm{Ti} \%}{\mathrm{~N} \%}\right)+20638 \\
& Z=\dot{\varepsilon} \exp \left(\frac{Q_{\mathrm{d}}}{R T}\right)=A(\sinh \alpha \sigma)^{w}
\end{aligned}
$$

where $\dot{\varepsilon}$ is the strain rate and $\sigma$ is the equivalent stress.

The activation energy $Q_{\mathrm{d}}$ is a parameter that is connected with the deformation mechanism and its value is related to the barrier to the climb of dislocations presented by the nanometric precipitates. Nonetheless, the increase obtained both for the peak stress and the activation energy in steels with the finest precipitate distribution is relatively small and barely represents an increase in the rolling forces. In Ti-containing steels, the driving forces of dynamic recrystallization are approximately two orders of magnitude greater than the pinning forces, and therefore the precipitation state (even for the finest sizes) is not able to impede the progress of dynamic recrystallization. The most notable influence of $\mathrm{Ti}$ is the grain refinement at the reheating temperatures seen above and the consequent reduction in the critical strain necessary for dynamic recrystallization to begin. 
The parameter Ti/N has also an important influence on the static recrystallization of austenite after deformation. The recrystallization kinetics can be described by an Avrami equation in the following way [42]:

$$
X_{\mathrm{a}}=1-\exp \left(-\ln 2\left(\frac{t}{t_{0.5}}\right)^{n}\right)
$$

where $X_{\mathrm{a}}$ is the fraction of the recrystallized volume and $t_{0.5}$ is the time corresponding to half of the recrystallized volume, which depends practically on all the variables intervening in hot deformation and whose most general expression follows a law of the type:

$$
t_{0.5}=A \varepsilon^{p} \dot{\varepsilon}^{q} D^{s} \exp \left(\frac{Q_{\mathrm{x}}}{R T}\right)
$$

where $\varepsilon$ is the strain, $\dot{\varepsilon}$ the strain rate, $D$ the grain size, $Q_{\mathrm{x}}$ the activation energy for recrystallization, $T$ the absolute temperature, $R=8.3145 \mathrm{~J} \cdot \mathrm{mol}^{-1} \cdot \mathrm{K}^{-1}$ and $p, q$ and $s$ are parameters. While $p$ and $q$ are negative values, $s$ is positive [2]. The activation energy $Q_{\mathrm{x}}$ is the parameter that basically reflects the influence of precipitation on the delay experienced by static recrystallization kinetics. Similarly to what happened with dynamic recrystallization and hot deformation, the increase in activation energy due to precipitates $\left(\Delta Q_{\mathrm{x}}\right)$ and $\mathrm{Ti} / \mathrm{N}$ follows a relationship that can be described with the curve shown in Fig. 5 or the equation [40]:

$$
\Delta Q_{\mathrm{x}}\left(\mathrm{J} \cdot \mathrm{mol}^{-1}\right)=-50527\left(\ln \frac{\mathrm{Ti} \%}{\mathrm{~N} \%}\right)^{2}-3262\left(\ln \frac{\mathrm{Ti} \%}{\mathrm{~N} \%}\right)+92485
$$


The highest value of the activation energy for static recrystallization $\Delta Q_{\mathrm{x}}$ corresponds to hypostoichiometric ratios close to 1 , i.e. with small precipitate sizes. Higher Ti/N ratios cause coarser sizes and it can even happen that the particles serve as a heterogeneous nucleation site for static recrystallization, i.e. $Q_{\mathrm{x}}$ is lower than the value obtained for a Ti-free steel, as seen in Fig. 5. However, a solute drag effect can be observed with very high $\mathrm{Ti} / \mathrm{N}$ values, so $\mathrm{Ti}$ in solution can delay recrystallization and contribute to an increase in $Q_{\mathrm{x}}$ value.

In sum, the addition of Ti usually delays static recrystallization kinetics, but the highest value of $\Delta Q_{\mathrm{x}}$ is around $90000 \mathrm{~J} \cdot \mathrm{mol}^{-1}$ (Fig. 5), which is much lower than the values found for $\mathrm{V}$ or $\mathrm{Nb}$ steels, as will be seen later. As a result, Ti is often insufficient to inhibit recrystallization during hot rolling. Figure 6 shows the typical shape of the curves of static recrystallization kinetics of Ti-microalloyed steels, where the recrystallized fraction $X_{\mathrm{a}}$ follows the sigmoidal shape of Avrami's law. In certain cases, as for high $\mathrm{Ti}$ additions and high $\mathrm{Ti} / \mathrm{N}$ ratios, a short plateau of inhibition of recrystallization by strain-induced precipitates can be observed [33].

The driving forces for static recrystallization in Ti-microalloyed steels are normally much higher than the pinning forces exerted by the TiN particles irrespective of the Ti and $\mathrm{N}$ contents and the deformation conditions. Therefore, the austenite may recrystallize completely between steps during hot rolling even at low temperatures. In fact, in most cases, the curves of hot rolling simulation determined by the method of Jonas et al. [43] do not show an increase in the slope of mean flow stress (MFS) represented versus the inverse of temperature or this change happens at temperatures near $A_{\mathrm{r} 3}$. In other words, the temperature of no-recrystallization ( $\left.T_{\mathrm{nr}}\right)$ does not exist, 
as shown in Fig. 7 or it is very low [44]. As will be seen later, the shape of MFS curves for V and especially Nb-microalloyed steels is usually different, as $T_{\mathrm{nr}}$ can be determined for a broad range of rolling conditions, indicating stronger recrystallization inhibition during hot rolling. However, the complete recrystallization of austenite between passes until low temperatures in Ti steels denotes that the austenite barely experiences hardening during and at the end of rolling, which means that ferrite grain size refinement cannot be significantly enhanced by thermomechanical processing in this family of steels. On the other hand, austenite grain size hardly varies during hot rolling. TiN precipitates exert a strong control of grain growth from the reheating temperature, and according to Eq. (10) the small initial grain size obtained in Ti steels after reheating (below $20 \mu \mathrm{m})$ accelerates recrystallization kinetics. As Fig. 8 shows, successive recrystallizations that occur during rolling do not serve to refine significantly austenite recrystallized grain size in a Timicroalloyed steel, while Nb and V-microalloyed steels start from coarser grain sizes and suffer a strong grain refinement during the first deformation passes [24, 45, 46]. As a result, it can be suggested that the hot rolling schedule of Ti-microalloyed steels could be simplified by suppressing several passes at intermediate temperatures [45]. To enhance ferrite grain size refinement, Ti steels should be processed by rolling to temperatures close to $A_{\mathrm{r} 3}$ and applying a fast cooling rate during $\gamma \rightarrow \alpha$ transformation.

It should be taken into account that $\mathrm{Ti}$ additions must be precisely controlled and limited to prevent harmful consequences in several aspects. On the one hand, coarse Ti-rich carbonitrides (mostly TiN) can have deleterious effects in toughness. These particles are strongly bonded to the matrix and, when they crack, they can act as potential cleavage fracture initiation nuclei [47-49]. On the other hand, the large TiN particles that form at high temperatures may be also detrimental 
to machinability [38], as these particles can be extremely hard and wear machining tools abrasively. This is shown by the shorter tool life when machining titanium alloyed steels [50].

High aluminum contents can also impair machinability [50]. Aluminum is an element whose impact on austenite microstructure and precipitation state is usually underestimated. The presence of AlN in the austenite generates harmful effects on the hot-ductility of different kinds of steels [51, 52]. Crystallographic structure of AlN is hexagonal (hcp). Nitrides and carbides of typical microalloying elements (Nb, V, Ti) have an fcc crystallographic structure. These compounds, especially in the case of the smallest particles, frequently form precipitates which are semicoherent with the (fcc) austenitic matrix. Their lattice parameter is slightly higher than that of the austenite [38].

Al can be detrimental for the control of austenite grain growth at high temperatures when this element is added to Ti-microalloyed steels [37, 53]. At equal level of microalloying, the precipitates are soluble in austenite as follows: $\mathrm{TiN}<\mathrm{AlN}<\mathrm{NbN}<\mathrm{VN}$, i.e. solubility temperature of AlN is generally lower than the temperature for TiN [27]. As a result, it has been found that AlN particles dissolve quickly at temperatures between 1000 and $1100{ }^{\circ} \mathrm{C}$, causing a drastic decline in the local pinning forces which gives rise to more pronounced abnormal growth (see Fig. 9) of the affected grains in steels with relatively high $\mathrm{Al}$ contents [54].

AlN particles are usually finer than TiN particles that often precipitate during reheating. However, it has been found that the mean size of strain-induced AlN precipitates is almost one order of magnitude bigger than the size of other particles such as $\mathrm{Nb}$ and $\mathrm{V}$ carbonitrides [55, 56]. The diameter of a particle at any temperature can be expressed as [57, 58]: 


$$
\Delta d^{2}=\beta^{2} D_{0} \exp \left(-\frac{Q_{\mathrm{d}}}{R T}\right) \Delta t
$$

where $\Delta d^{2}=d^{2}-d_{0}^{2}$ and $\Delta t=t-t_{0}$. Here, $d_{0}$ is the particle diameter at time $t_{0}, \beta$ is the growth coefficient and $D_{0} \exp \left(-\frac{Q_{\mathrm{d}}}{R T}\right)$ is the diffusion coefficient (D) of the different elements in austenite. This coefficient is represented as a function of temperature for different elements in Fig. 10 [57, 59, 60]. The larger diffusion coefficient in austenite of Al compared to other elements (almost two orders of magnitude) together with the higher solubility temperatures of AlN (especially when compared to $\mathrm{V}$ precipitates) are the main reasons for the coarser size of AlN particles. As a result, the pinning forces exerted by coarse AlN precipitates are weak and accordingly (as occurred with TiN particles) the static recrystallization of austenite is not significantly inhibited by these particles. Figure 11 shows the curves of static recrystallization kinetics of an Al-microalloyed steel with a very short plateau that indicates that the distribution of AlN particles is not very effective in inhibiting static recrystallization. In fact, the increase in activation energy for austenite recrystallization due to the presence of AlN is usually much lower when compared to $\mathrm{V}$ or Nb-microalloyed steels, which reveals the difficulty in achieving austenite strengthening during hot rolling through the effect of AlN pinning particles [56]. It is interesting to note that recrystallization kinetics obeys Avrami' s law before the start of the plateau and after its finish.

A reduction in the $\mathrm{Al}$ content in microalloyed steels can be beneficial because $\mathrm{Al}$ traps part of the $\mathrm{N}$ so reducing the precipitated volume of $\mathrm{NbCN}$ or $\mathrm{VCN}$ particles. A decrease in $\mathrm{Al}$ content can 
help to augment pinning forces and contribute to a more intense strengthening of the austenite during and at the end of hot rolling, thereby increasing the number of potential sites for the nucleation of ferrite [55].

Solubility temperatures of niobium carbonitrides are usually lower than the temperatures for TiN and AlN but higher than for VCN. On the other hand, Fig. 10 shows that Nb presents a slightly higher diffusion coefficient than V. Therefore, as explained for Al, NbCN particles can then be expected to be usually coarser than VN [61]. However, the typical range of precipitation temperatures of $\mathrm{NbCN}$ makes $\mathrm{Nb}$ an ideal element to inhibit static recrystallization during hot rolling, even at very low contents. The isothermal curves of static recrystallization versus time for $\mathrm{Nb}$ steels show normally long plateaus of recrystallization inhibition. These curves sometimes display a double plateau (Fig. 12) that results from the precipitation of two types of carbonitrides which start to form at very similar temperatures [6].

Recrystallized fraction curves can be used to plot recrystallization-precipitation-time-temperature (RPTT) diagrams (Fig. 13) as described elsewhere [6, 62]. RPTT diagrams provide useful information on aspects such as recrystallization-precipitation interaction or duration of precipitation. These diagrams also help to determine the activation energy for recrystallization $Q_{\mathrm{x}}$ before and after precipitation (Fig. 14). In $\mathrm{Nb}$ or $\mathrm{V}$-microalloyed steels, $Q_{\mathrm{x}}$ after strain-induced precipitation reaches values that are between two and three times those corresponding to the previous state, when all the elements are in solution [6]. Compared to $\mathrm{Ti}$ and $\mathrm{Al}$ steels, this increase of $Q_{\mathrm{x}}$ is much more remarkable. 
Under certain hot rolling conditions (short interpass times $\Delta t$ and small values of pass strain $\varepsilon$ ), an addition of less than $0.01 \mathrm{wt} . \%$ of $\mathrm{Nb}$ in the steel may be sufficient to inhibit the static recrystallization of austenite and to achieve fine final microstructures [63]. Compared to Fig. 7, the curve of MFS versus the inverse of temperature in $\mathrm{Nb}$ steels usually presents a change in the slope that indicates a greater tendency to strengthening due to the incomplete recrystallization between passes. This change occurs at the temperature of no-recrystallization $\left(T_{\mathrm{nr}}\right)$, as shown in Fig. 15. By means of thermomechanical tests and metallographic studies, it can be verified that $T_{\mathrm{nr}}$ approximately corresponds to the temperature where recrystallization starts to be incomplete. However, incomplete recrystallization is visually evident at temperatures $50{ }^{\circ} \mathrm{C}$ below $T_{\mathrm{nr}}$, where grain elongation and increase in aspect ratio of the grains with temperature drop start to be significant $[24,46]$. This can be seen in Fig. 16a-n, which presents the evolution of austenite microstructure during a hot rolling simulation of a medium carbon vanadium microalloyed steel. The strong grain refinement achieved in the first rolling passes shown in Fig. 8 can be appreciated as well in this figure. $T_{\text {nr }}$ does not always coincide with the start of strain-induced precipitation, as some fraction of precipitation can occur at temperatures above $T_{\mathrm{nr}}$ [63]. Figure 17 shows an example of the aspect of $\mathrm{NbCN}$ precipitates in austenite during hot rolling.

Thermomechanical simulation also makes it possible to know the apparent $A_{\mathrm{r} 3}$ transformation temperature and even the apparent $A_{\mathrm{r} 1}$ eutectoid temperature [64] for low carbon contents [63]. On the other hand, the magnitude known as "accumulated stress" $(\Delta \sigma)$ can be determined simultaneously and will be given by the length of the vertical segment drawn between the straight regression lines of phases I and II, as illustrated in Fig. 15. $\Delta \sigma$, which reaches its highest value at 
$A_{\mathrm{r} 3}$, is a direct and precise assessment of the progressive strengthening of austenite at temperatures below $T_{\mathrm{nr}}[46]$.

The value of $T_{\text {nr }}$ decreases significantly with increasing pass strain $\varepsilon[43,63]$ and the same can be said for the value of $\Delta \sigma$ [65]. This results from the acceleration of recrystallization due to the higher stored energy and the successive recrystallizations of austenite at high temperatures (above $T_{\text {nr }}$ ). The influence of interpass time $(\Delta t)$ is complex: for very short interpass times, the solute drag effect can be observed, so $T_{\mathrm{nr}}$ strongly decreases for increasing times [43]. At longer values of $\Delta \mathrm{t}$, the increasing volume fraction of fine precipitates makes $T_{\mathrm{nr}}$ to increase. Finally, the coarsening of precipitates appears for long interpass times (approximately above 30-60 s) so $T_{\mathrm{nr}}$ values drop [63, 65]. Strain induced coarsening of precipitates brings about that the decrease of $T_{\mathrm{nr}}$ for higher strains is stronger at long interpass times. On the other hand, the value of $\Delta \sigma$ usually decreases for longer $\Delta t[63,65]$. As a result, in order to obtain strongly deformed austenite microstructures before the $\gamma \rightarrow \alpha$ transformation it is generally advisable to reduce the interpass time and the magnitude of the strain applied in the final passes.

The microstructure of deformed austenite, characterized by a higher value of $\Delta \sigma$, contains higher dislocation density within the grains, more elongated grains that increase the grain boundary area per unit volume and ledges in the grain boundaries. All these aspects contribute to increasing the nucleation rate of ferrite during cooling and to refine the ferrite grain size [66, 67]. Figure 18a-d shows the microstructure obtained after different thermomechanical processing routes on a $\mathrm{Nb}$ microalloyed steel. Shorter interpass times increase the value of $\Delta \sigma$ at the end of hot rolling, which ensures a finer size of ferrite after cooling from austenite. The influence of pass strain 
cannot be seen clearly in the figure: on the one hand, higher strains accelerate recrystallization and reduce the value of $\Delta \sigma$, but on the other hand the austenite recrystallization hardly occurs during cooling so the last deformation is accumulated in the austenite. As a result, a higher value of strain in the last pass can provide more potential sites for the nucleation of ferrite so enhancing grain refinement.

One of the most interesting technical advantages of vanadium microalloying is its contribution to enhancing ferrite grain refinement thanks to the intragranular nucleation of ferrite on VN or VCN precipitates. If samples of a V-microalloyed steel are cooled after different post-deformation isothermal holding times corresponding to the beginning and the end of the plateau of inhibition of recrystallization, it is found that the existence of a distribution of strain-induced VCN precipitates at the end of the plateau leads to a significant decrease in the grain size, close to 50 \%, as Fig. 19 shows. VCN precipitates can serve as nucleation sites for very fine (close to 1 micron size) ferritic grains (see Fig. 20) [68]. The intragranular nucleation on precipitates is an important contribution to the ferrite grain refinement, although the nucleation of the ferrite on austenite grain boundaries and dislocations within the grains is usually more important. The positive influence of intragranular nucleation on precipitates is comparatively stronger for low strains applied. An increase in the strain favors nucleation of ferrite on austenite recrystallized grain boundaries, as the austenite grain is finer, and on subgrains, in preference to intragranular nucleation on VN-precipitates [69, 70].

Figure 21 shows that the value of accumulated stress $(\Delta \sigma)$ obtained at the end of hot rolling simulation of a certain family of steels provides important information about the chances to 
achieve ferrite grain refinement after cooling. Analogous graphs where the ferrite grain size is plotted against the absolute value of MFS measured at the end of rolling simulation have been presented by other authors [71, 72]. The data of Fig. 21 come from steels with different amounts of carbon and other alloying elements and slight variations in processing schedule and final rolling temperature, but this graph is a useful orientation. In general, Ti-microalloyed steels offer coarser ferrite grain sizes compared to $\mathrm{Nb}$ microalloyed steels, where the value of $T_{\mathrm{nr}}$ is usually higher. On the other hand, the phenomenon of intragranular nucleation of ferrite on VCN particles can contribute to a stronger ferrite grain refinement in V-microalloyed steels. The aforementioned complex influence of pass strain can be observed: in general, a lower value of strain generates higher values of $\Delta \sigma$, but for a constant $\Delta \sigma$, the application of higher strains in the last pass enhances grain refinement due to the accumulation of the last deformation in the austenite. It is known that a simultaneous improvement in mechanical properties of strength and toughness with ferrite grain refinement can be expected according to the published equations that relate yield strength and impact transition temperature to ferrite grain size [38, 73]. Finally, a positive synergetic effect on ferrite grain size and consequently on mechanical properties can be obtained from the combined application of microalloying, improved thermomechanical processing routes and accelerated cooling [74].

\section{Conclusion}

Microalloying elements dissolved in austenite have a considerable effect on microstructure, but the main reason for the presence of these elements in microalloyed steels lies in their 
precipitation. Precipitates of the microalloying elements play a major role in several aspects of the thermomechanical processing of steels such as the austenite grain growth, static recrystallization kinetics and phase transformation. Titanium is the most effective element to control grain growth at high reheating temperatures and a hypostoichiometric $\mathrm{Ti} / \mathrm{N}$ ratio close to 2 is recommended. Ti/N ratio also affects hot deformation behavior and static recrystallization. The static recrystallization kinetics in Ti-microalloyed steels is fast due to the fine initial austenite grain size and the much higher value of the recrystallization driving forces compared to the pinning forces exerted by TiN particles precipitated at high temperatures. During rolling, the austenite in Ti-steels experiences a minor reduction in austenite grain size in the first passes and a limited hardening below $T_{\mathrm{nr}}$. At medium reheating temperatures, aluminum can help to control grain growth, but its addition to Ti steels can be harmful because it promotes abnormal grain growth at temperatures near $1100{ }^{\circ} \mathrm{C}$. The inhibition of static recrystallization by AlN particles is not remarkable, whereas niobium carbonitrides are very effective in hindering static recrystallization of austenite during hot rolling, due to their adequate precipitation temperature range at deformation temperatures and strong pinning effect. This is seen in the high values of activation energy $\left(Q_{\mathrm{x}}\right)$ after precipitation, no-recrystallization temperature $\left(T_{\mathrm{nr}}\right)$ and accumulated stress $(\Delta \sigma)$, which is a property that helps to characterize the progressive strengthening of austenite due to its incomplete recrystallization below $T_{\mathrm{nr}}$ and informs about the density of potential nucleation sites for ferrite. A significant relationship between the value of $\Delta \sigma$ measured at the end of rolling (just before cooling) and the final ferritic grain size can be described. Finally, particles of vanadium carbonitrides (precipitated at lower temperatures than NbCN) can serve as preferential sites for the intragranular nucleation ferrite and help to enhance the ferrite grain refinement. 


\section{References}

[1] J. J. Jonas, M. G. Akben: Metals Forum 4 (1981) 92.

[2] S. F. Medina, A. Quispe: ISIJ Int. 41 (2001) 774.

[3] M. Hillert: Acta Mater. 52 (2004) 5289. DOI: 10.1016/j.actamat.2004.07.032

[4] S. G. Kim, Y. B. Park: Acta Mater. 56 (2008) 3739. DOI: 10.1016/j.actamat.2008.04.007

[5] ～L. Bäcke: ISIJ Int. 50 (2010) 239. DOI: 10.2355/isijinternational.50.239

[6] S. F. Medina, A. Quispe, M. Gomez: Mater. Sci. Technol. 19 (2003) 99. DOI: $10.1179 / 026708303225008662$

[7] C. S. Smith: Trans. Metall. Soc. AIME 175 (1948) 15.

[8] P. A. Manohar, M. Ferry, T. Chandra: ISIJ Int. 38 (1998) 913.

[9] M. Hillert: Acta Metall. 13 (1965) 227.

[10] T. Gladman: Proc. R. Soc. London 294 (1966) 298.

[11] T. Gladman, F. B. Pickering: J. Iron Steel Inst. 205 (1967) 653.

[12] M. F. Ashby, J. Harper, J. Lewis: Trans. Metall. Soc. AIME 245 (1969) 413.

[13] V. Randle, B. Ralph: Acta Metall. 35 (1986) 891.

[14] T. Gladman: Mater. Sci. Forum 94-96 (1992) 113.

[15] H. Adrian, F. B. Pickering: Mater. Sci. Technol. 7 (1991) 1762.

[16] M. Toloui, M. Militzer: Int. J. Mat. Res. 101 (2010) 542. DOI: 10.3139/146.110308

[17] P. Schaffnit, C. Stallybrass, J. Konrad, A. Kulgemeyer, H. Meuser: Int. J. Mat. Res. 101 (2010) 549. DOI: 10.3139/146.110309

[18] S. S Hansen, J. B. Van der Sande, M. Cohen: Metall. Trans. A 11 (1980) 387. 
[19] L. J. Cuddy, in: A. J. DeArdo, G. A. Ratz, P. J. Wray (Eds.), Proc. Int. Conf. Thermomechanical Processing of Microalloyed Austenite, The Metallurgical Society of AIME, Pittsburgh, PA, USA (1982) 129.

[20] H. Réglé: Int. J. Mat. Res. 101 (2010) 326. DOI: 10.3139/146.110291

[21] D. Helm: Int. J. Mat. Res. 101 (2010) 972. DOI: 10.3139/146.110369

[22] A. Faessel: Rev. Métall. Cah. Inf. Tech. 33 (1976) 875.

[23] H. L. Andrade, M. G. Akben, J. J. Jonas: Metall. Trans. A 14 (1983) 1967.

[24] M. Gómez, L. Rancel, S. F. Medina: Met. Mater. Int. 15 (2009) 689. DOI: $10.1007 / \mathrm{s} 12540-009-0689-0$

[25] J. S. Perttula, L. P. Karjalainen: Mater. Sci. Technol. 14 (1998) 626.

[26] K. Narita: Trans. ISIJ 15 (1975) 145.

[27] E. T. Turkdogan: Iron Steelmaker 1661 (1989).

[28] K. Inoue, I. Ohnuma, H. Ohtani, K. Ishida, T. Nishizawa: ISIJ Int. 38 (1998) 991.

[29] F. B. Pickering, in: T. N. Baker (Ed.), Titanium Technology in Microalloyed Steels, The Institute of Materials, London, UK (1997) 10.

[30] S. Shanmugam, N. K. Ramisetti, R. D. K. Misra, J. Hartmann, S.G. Jansto: Mater. Sci. Eng. A 478 (2008) 26. DOI: 10.1016/j.msea.2007.06.003

[31] K. Banerjee, M. Militzer, M. Perez, X. Wang: Metall. Mater. Trans. A 41 (2010) 3161. DOI: $10.1007 / s 11661-010-0376-2$

[32] R. Wang, C. I. Garcia, M. Hua, K. Cho, H. Zhang, A. J. DeArdo: ISIJ Int. 46 (2006) 1345. DOI: $10.2355 /$ isijinternational.46.1345

[33] M. I. Vega, S. F. Medina, A. Quispe, M. Gomez, P. P. Gomez: ISIJ Int. 45 (2005) 1878. DOI: 10.2355/isijinternational.45.1878 
[34] J. I. Chaves, S. F. Medina, M. Gomez, L. Rancel, P. Valles: Mater. Sci. Forum 550 (2007) 405. DOI: $10.4028 / 0-87849-434-0.405$

[35] I. M. Lifshitz, V. V. Slyozov: J. Phys. Chem. Solids 19 (1961) 35.

[36] J. Kunze, C. Mickel, G. Backmann, B. Beyer, M. Reibold, C. Klinkenberg: Steel Res. 68 (1997) 441.

[37] S. F. Medina, M. Chapa, P. Valles, A. Quispe, M. I. Vega: ISIJ Int. 39 (1999) 930.

[38] T. Gladman: The Physical Metallurgy of Microalloyed Steels, The Institute of Materials, London, UK (1997).

[39] J.-R. Yim, A.-R. Min, Y.-C. Joo: Met. Mater. Int. 15 (2009) 113. DOI: 10.1007/s12540009-0113-9

[40] S. F. Medina, M. I. Vega, M. Gomez, P. P. Gomez: ISIJ Int. 45 (2005) 1307. DOI: 10.2355/isijinternational.45.1307

[41] J. H. Beynon, C. M. Sellars: ISIJ Int. 32 (1992) 359.

[42] C.M. Sellars, in: C.M. Sellars, C.J. Davies (Eds.), Proc. Int. Conf. on Hot Working and Forming Processes, The Metal Society, London, UK (1980) 3.

[43] D. Q. Bai, S. Yue, W. P. Sun, J. J. Jonas: Metall. Trans A 24 (1993) 2151.

[44] M. I. Vega, S. F. Medina, A. Quispe, M. Gomez, P. P. Gomez: Mater. Sci. Eng. A 423 (2006) 253. DOI: 10.1016/j.msea.2006.02.037

[45] M. Gomez, L. Rancel, P. P. Gomez, J. I. Robla, S. F. Medina: ISIJ Int. 50 (2010) 868. DOI: 10.2355/isijinternational.50.868

[46] M. Gómez, L. Rancel, B. J. Fernandez, S. F. Medina: Mater. Sci. Eng. A 501 (2009) 188. DOI: 10.1016/j.msea.2008.09.074

[47] M. J. Balart, C. L. Davis, M. Strangwood: Mater. Sci. Eng. A 328 (2002) 48. DOI: 10.1016/S0921-5093(01)01679-3. 
[48] A. Echeverria, J.M. Rodriguez-Ibabe: Scripta Mater. 50 (2004) 307. DOI: 10.1016/j.scriptamat.2003.09.003.

[49] H. Bomas, M. Bacher-Hoechst, R. Kienzler, S. Kunow, G. Loewisch, F. Muehleder, R. Schroeder: Fatigue Fract. Eng. Mater. Struct. 33 (2010) 126. DOI: 10.1111/j.14602695.2009.01423.x.

[50] V. Ollilainen, H. Pöntinen, M. Paju: European Patent EP 0265402B1 (1991).

[51] B. Mintz, J. M. Arrowsmith, in: C.M. Sellars, C.J. Davies (Eds.), Proc. Int. Conf. on Hot Working and Forming Processes, The Metal Society, London, UK (1980) 99.

[52] G. D. Funnell, in: C.M. Sellars, C.J. Davies (Eds.), Proc. Int. Conf. on Hot Working and Forming Processes, The Metal Society, London, UK (1980) 104.

[53] J. M. Cabrera, A. Al Omar, J. M. Prado: Z. Metallkd. 89 (1998) 47.

[54] S. F. Medina, M. Chapa, M. Gómez, A. Quispe, V. López, B. Fernández: Rev. Metal. Madrid 39 (2003) 408.

[55] M. Gómez, L. Rancel, S. F. Medina: Mater. Sci. Eng. A 506 (2009) 165. DOI: 10.1016/j.msea.2008.11.049

[56] M. Gómez, L. Rancel, S. F. Medina: Mater. Sci. Forum 638-642 (2010) 3388. DOI: 10.4028/www.scientific.net/MSF.638-642.3388

[57] H. Oikawa, Tetsu-to-Hagane 68 (1982) 1489.

[58] S. Okaguchi, T. Hashimoto: ISIJ Int. 32 (1992) 283.

[59] A. Vignes, J. Philebert, J. Badía, J. Lavasseur, in: Proc. 2nd Natl. Conf. Microprobe Analysis, Boston, USA (1967) Paper 20.

[60] J. D. Fast: Interaction of Metals and Gases, Macmillan New York, London, UK (1976) 221. 
[61] S. F. Medina, M. Gomez, P. P. Gomez: J. Mater. Sci. 45 (2010) 5553. DOI: $10.1007 /$ s10853-010-4616-z

[62] S. F. Medina, A. Quispe, P. Valles, J. L. Baños: ISIJ Int. 39 (1999) 913.

[63] M. Gomez, S. F. Medina, A. Ouispe, P. Valles: ISIJ Int. 42 (2002) 423.

[64] M. Gómez, S. F. Medina, G. Caruana: ISIJ Int. 43 (2003) 1228.

[65] M. Gomez, O. Hernanz, S. F. Medina, P. Tarin: Steel Res. 73 (2002) 446.

[66] M. Umemoto, A. Hiramatsu, A. Moriya, T. Watanabe, S. Nanba, N. Nakajima, G. Anan, Y. Higo: ISIJ Int. 32 (1992) 306.

[67] Q. Yu, Z. Wang, X. Liu, G. Wang: ISIJ Int. 44 (2004) 710.

[68] S. F. Medina, M. Gómez, L. Rancel: Scripta Mater. 58 (2008) 1110. DOI: 10.1016/j.scriptamat.2008.02.004

[69] S. F. Medina, M. Gómez, J. I. Chaves, P. P. Gómez, P. Adeva: Mater. Sci. Forum 500-501 (2005) 371.

[70] S. F. Medina, L. Rancel, M. Gómez, R. Ishak, M. De Sanctis: ISIJ Int. 48 (2008) 1603. DOI: $10.2355 /$ isijinternational.48.1603

[71] A. Najafi-Zadeh, S. Yue, J. J. Jonas: ISIJ Int. 32 (1992) 213.

[72] L. P. Karjalainen, T. M. Maccagno, J. J. Jonas: ISIJ Int. 35 (1995) 1523.

[73] F. B. Pickering: Physical Metallurgy and the Design of Steels, Science Publishers, London, UK (1978) 66.

[74] A. J. DeArdo, M. J. Hua, K. G. Cho, C. I. Garcia: Mater. Sci. Technol. 25 (2009) 1074. DOI: $10.1179 / 174328409 X 455233$ 


\section{Correspondence address}

Dr. Manuel Gómez

Department of Physical Metallurgy

National Center for Metallurgical Research (CENIM-CSIC), Av. Gregorio del Amo 8; 28040-

Madrid, Spain

Tel.: +34 $915538900(348)$

Fax: +34 915347425

e-mail: mgomez@cenim.csic.es 


\section{List of figure captions}

Fig. 1. TEM image of a carbon replica showing fine TiN precipitates in a Ti microalloyed steel reheated at $1300{ }^{\circ} \mathrm{C}$ and quenched. Steel G.

Fig. 2. Austenite grain size measured after reheating at $1300{ }^{\circ} \mathrm{C}$ in several steels with $0.1 \% \mathrm{C}$ represented versus their Ti/N ratio. Steels A, C, D, E, F, G, H.

Fig. 3. Mean particle size of fine TiN precipitates (smaller than $100 \mathrm{~nm}$ ) after reheating at 1300 ${ }^{\circ} \mathrm{C}$ in several $0.1 \% \mathrm{C}$ steels as a function of their Ti/N ratio. Steels B, C, E, F, G, H.

Fig. 4. Increment of the activation energy $\left(\Delta Q_{\mathrm{d}}\right)$ for deformation of several $0.1 \% \mathrm{C}$ Ti-steels with regard to a Ti-free steel of the same composition. Steels B, C, D, E, G.

Fig. 5. Increment of the activation energy for static recrystallization $\left(\Delta Q_{\mathrm{x}}\right)$ of several $0.1 \% \mathrm{C} \mathrm{Ti}$ steels with regard to a Ti-free steel of the same composition. Steels A, B, C, E, G.

Fig. 6. Recrystallized fraction $\left(X_{\mathrm{a}}\right)$ versus time $(t)$ for a Ti-steel (Steel E).

Fig. 7. Dependence of Mean Flow Stress (MFS) on inverse of absolute temperature for a low carbon Ti-microalloyed steel (Steel F). The no-recrystallization temperature $\left(T_{\mathrm{nr}}\right)$ does not exist, i.e. recrystallization between passes is practically complete until $A_{\mathrm{r} 3}$ temperature. 
Fig. 8. Evolution of austenite grain size from reheating to temperatures close to $T_{\mathrm{nr}}$ during hot rolling simulations of three microalloyed steels with $0.017 \% \mathrm{Ti}, 0.007 \% \mathrm{Nb}$ and $0.13 \% \mathrm{~V}$ (Steels F, K, O, respectively).

Fig. 9. Example of abnormal austenite grain growth in Steel I (0.037 \% Al). Relatively high levels of $\mathrm{Al}$ in Ti-microalloyed steels can facilitate local drop of pinning forces due to the dissolution of AlN.

Fig. 10. Diffusion coefficients in austenite for the main microalloying elements and N.

Fig. 11. Recrystallized fraction $\left(X_{\mathrm{a}}\right)$ versus time $(t)$ for Steel $\mathrm{J}(0.037 \% \mathrm{Al})$.

Fig. 12. Recrystallized fraction $\left(X_{\mathrm{a}}\right)$ versus time $(t)$ for a low carbon Nb-microalloyed steel (steel L). The curves show a double plateau associated to two types of Nb precipitates with similar solubility temperatures.

Fig. 13. RPTT diagram of Steel M.

Fig. 14. Plot of $t_{0.5}$ against the reciprocal of the absolute temperature and determination of $Q_{\mathrm{x}}$ for Steel M.

Fig. 15. Dependence of Mean Flow Stress (MFS) on inverse of absolute temperature for a low carbon Nb-microalloyed steel (Steel L). The no-recrystallization temperature $\left(T_{\mathrm{nr}}\right)$ is the temperature below which the recrystallization between passes starts to be incomplete. 
Fig. 16. Microstructures obtained at different stages of a hot rolling simulation on a mediumcarbon V-microalloyed steel (Steel O). Pass strain $=0.20$; Strain rate $=3.63 \mathrm{~s}^{-1}$; Interpass time $=$ $20 \mathrm{~s}$; “Td” means deformation temperature and "Tq" quenching temperature.

Fig. 17. TEM image showing fine NbCN precipitates in a Nb-microalloyed steel (Steel N). Hot rolling simulation of 13 passes: reheating temperature $=1250{ }^{\circ} \mathrm{C}, \varepsilon=0.20, \Delta t=100 \mathrm{~s}$, last deformation pass at $850{ }^{\circ} \mathrm{C}$, quenching at $825^{\circ} \mathrm{C}$. Carbon extraction replica.

Fig. 18. Ferrite-pearlite microstructures obtained after hot rolling simulations carried out under different conditions followed by argon cooling from $825^{\circ} \mathrm{C}$. Steel M. (a) $\varepsilon=0.20, \Delta t=20 \mathrm{~s}$ (b) $\varepsilon$ $=0.35, \Delta t=20 \mathrm{~s}$. (c) $\varepsilon=0.20, \Delta t=500 \mathrm{~s}$. (d) $\varepsilon=0.35, \Delta t=500 \mathrm{~s}$.

Fig. 19. Ferrite grain size versus recrystallized austenite fraction in a V-microalloyed steel (Steel P). Grain size drops as post-deformation isothermal holding time increases and precipitated fraction grows.

Fig. 20. SEM-FEG image showing a small ferrite grain and a large VN precipitate in Steel P. Reheating temperature $=1230{ }^{\circ} \mathrm{C} \times 10 \mathrm{~min}$. Deformation temperature $=950{ }^{\circ} \mathrm{C} ; \varepsilon=0.35$; Postdeformation holding time $=900 \mathrm{~s}$. 
Fig. 21. Ferrite grain size as a function of accumulated stress $(\Delta \sigma)$ obtained at the end of hot rolling simulations carried out under different conditions of pass strain and interpass time on several low carbon microalloyed steels (Steels A, B, C, D, E, G, L, M, N, Q). 


\section{List of table captions}

Table 1. Chemical composition of the steels studied (wt.\%). 
$40 \mathrm{~nm}$ 


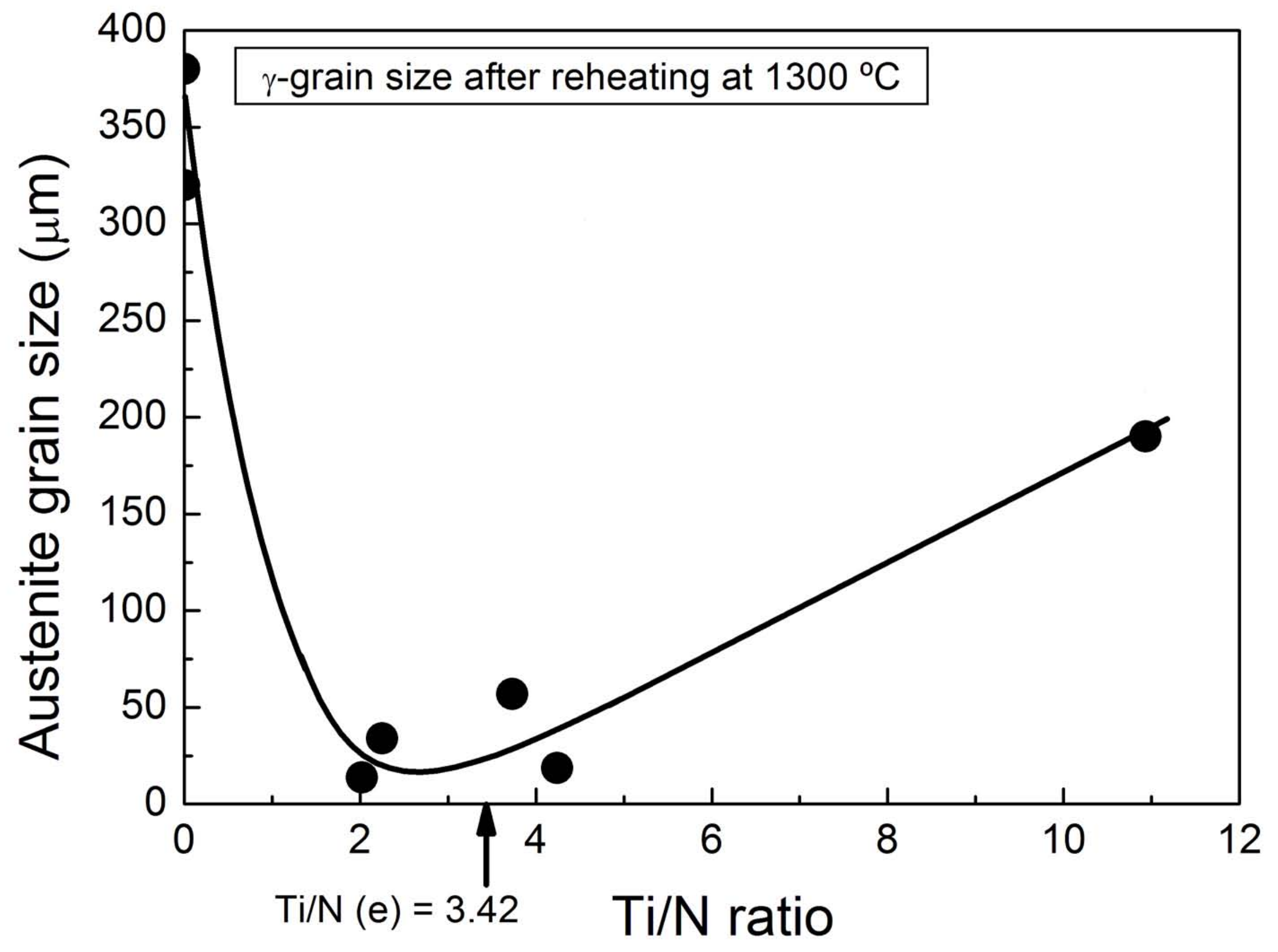




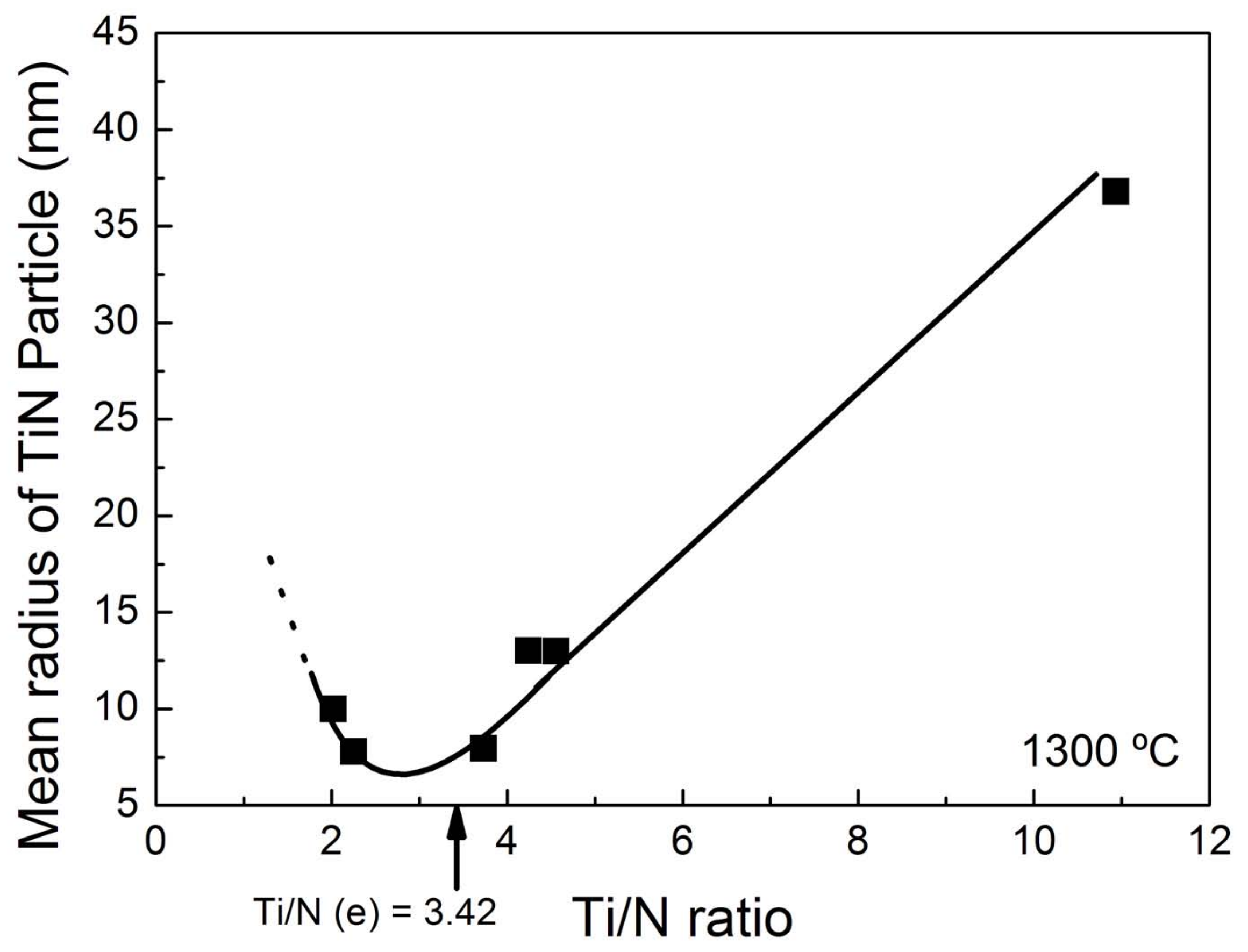




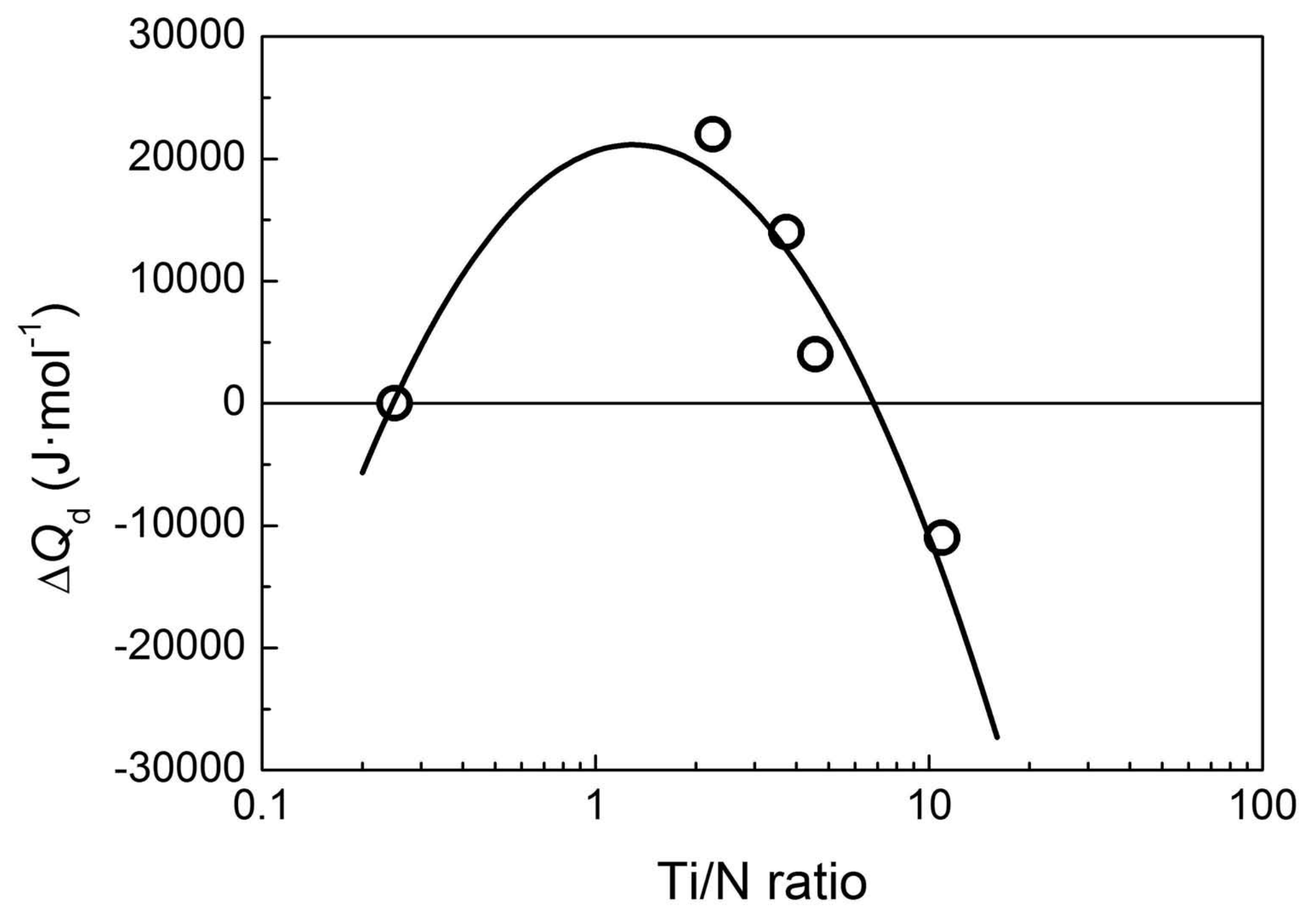




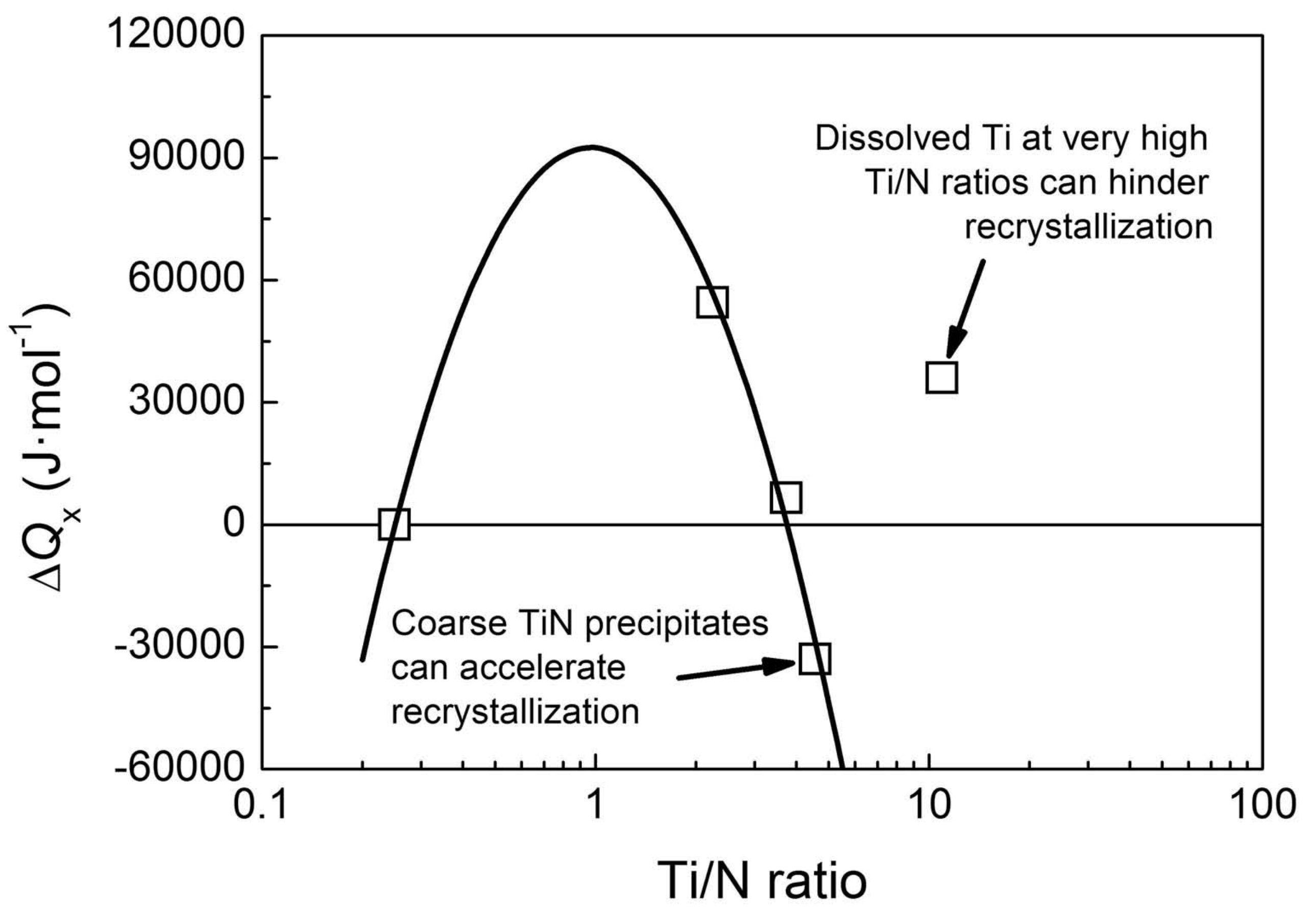




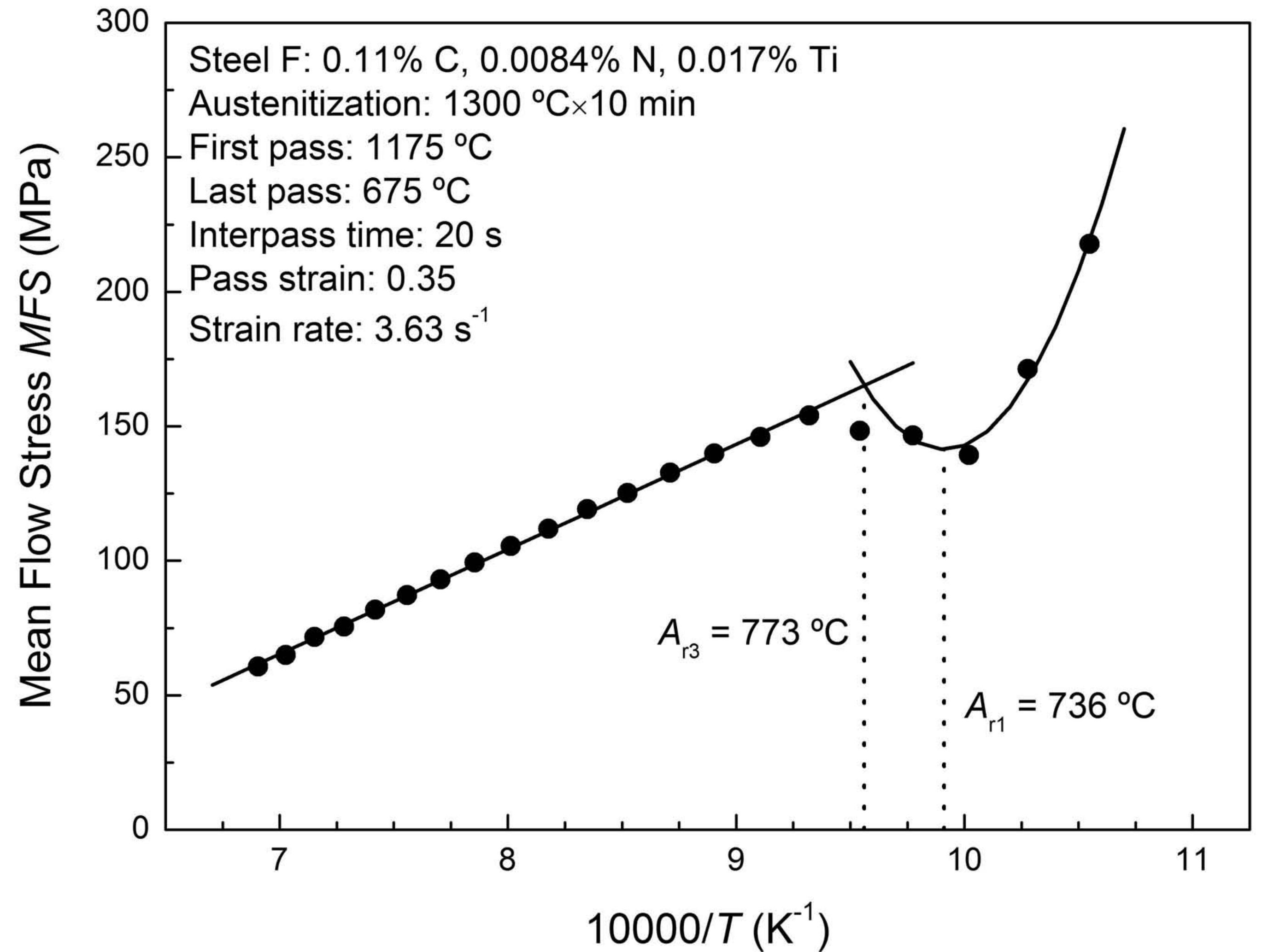




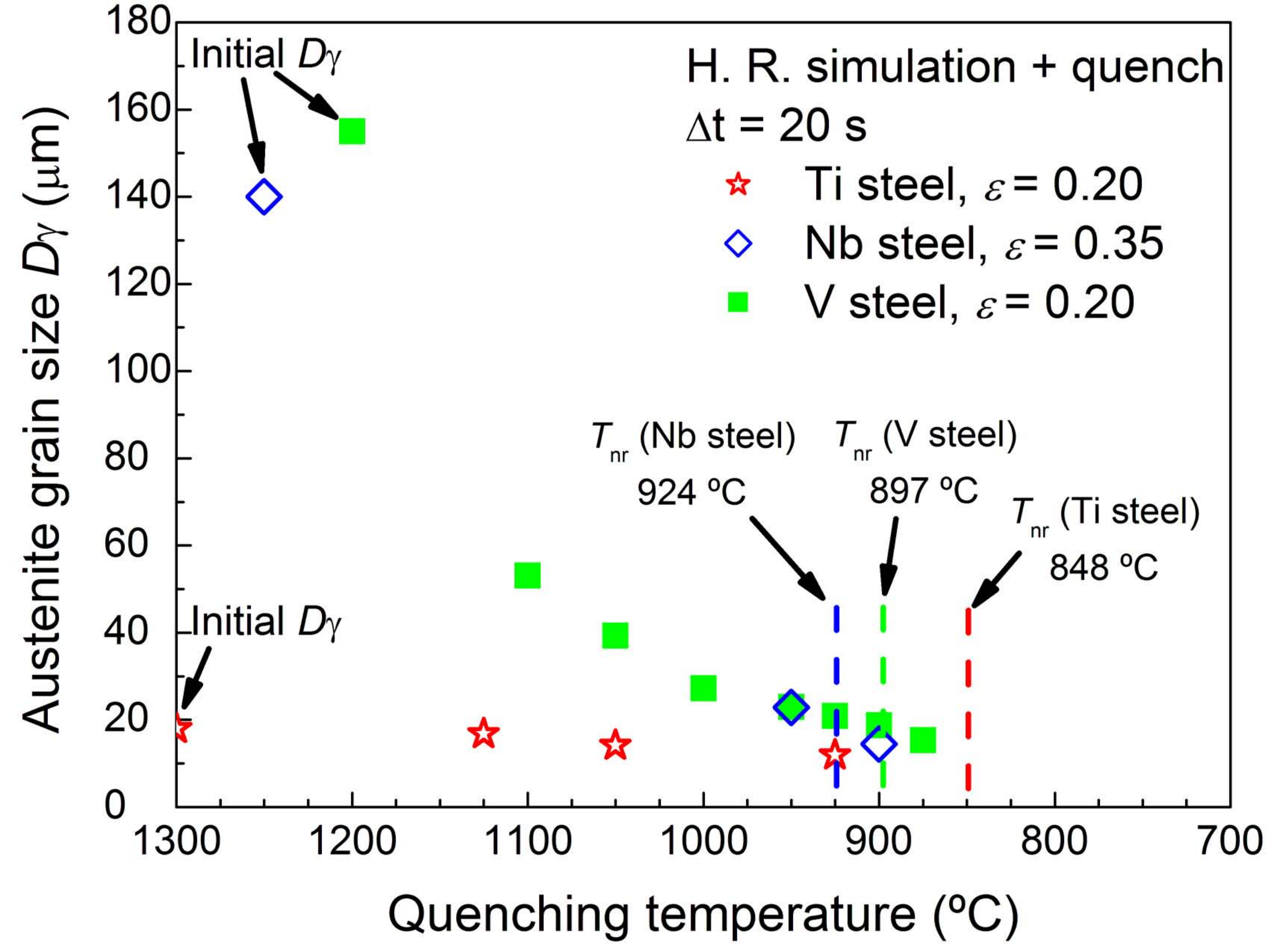




\section{(}

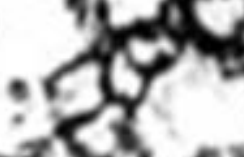
ionst?

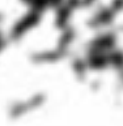




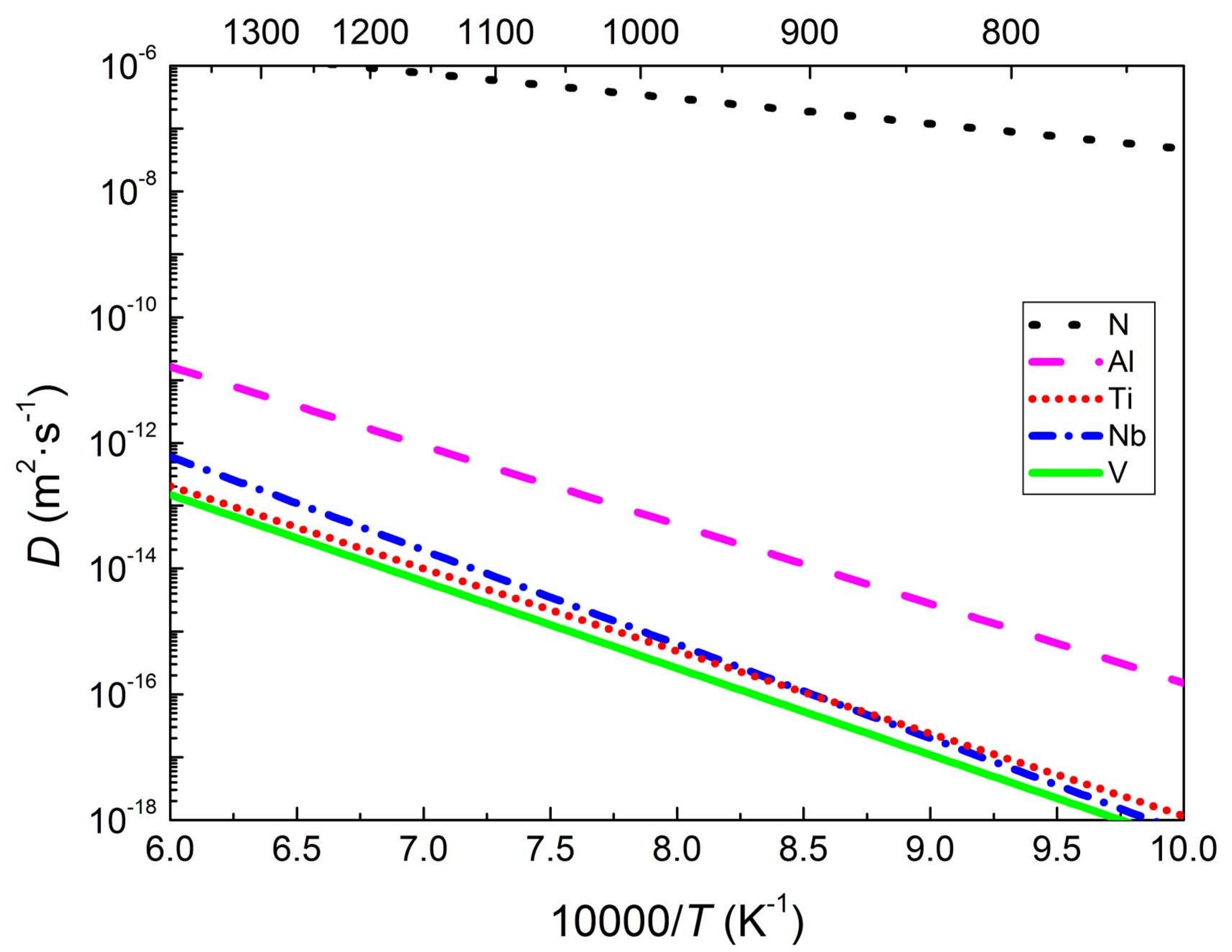




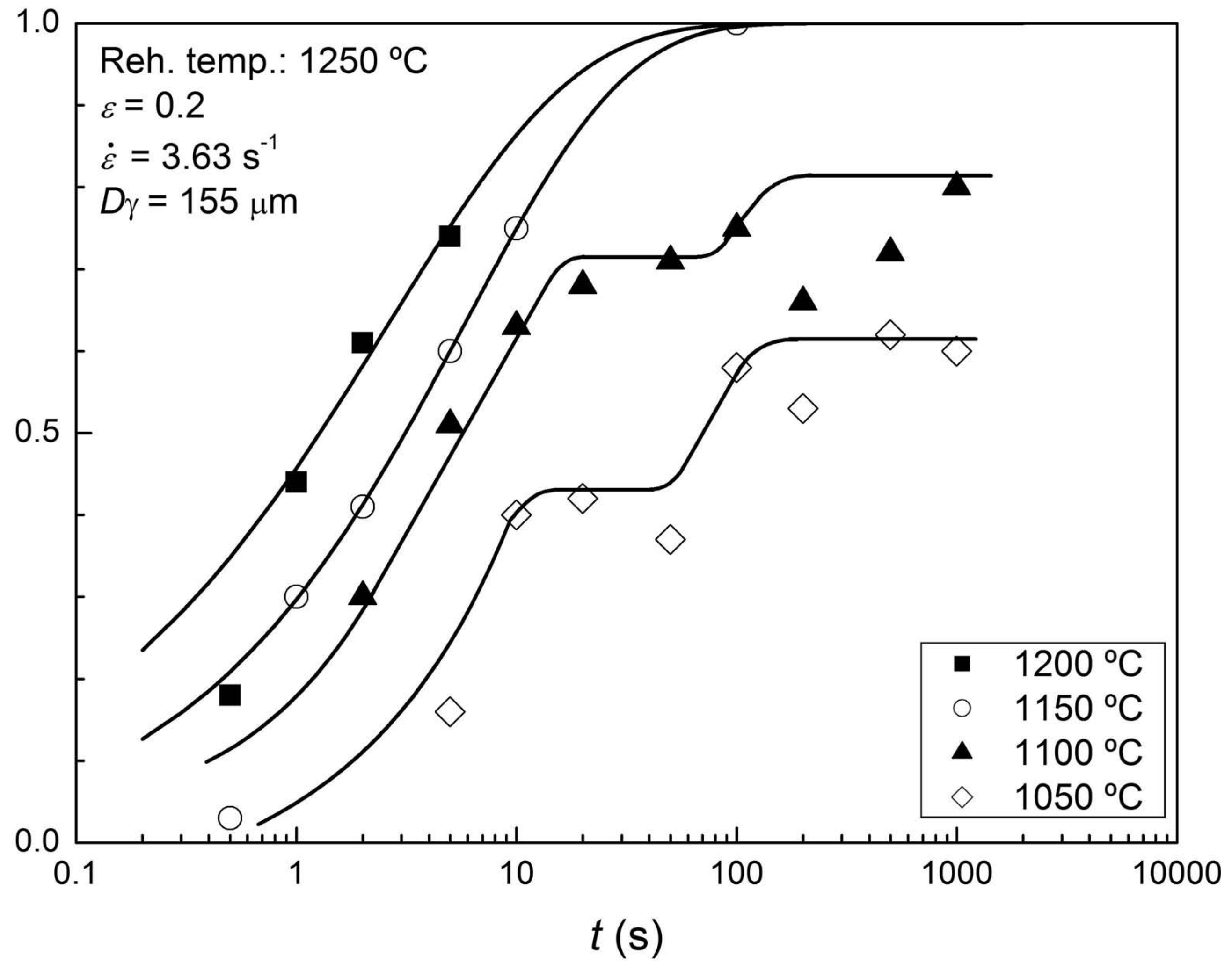




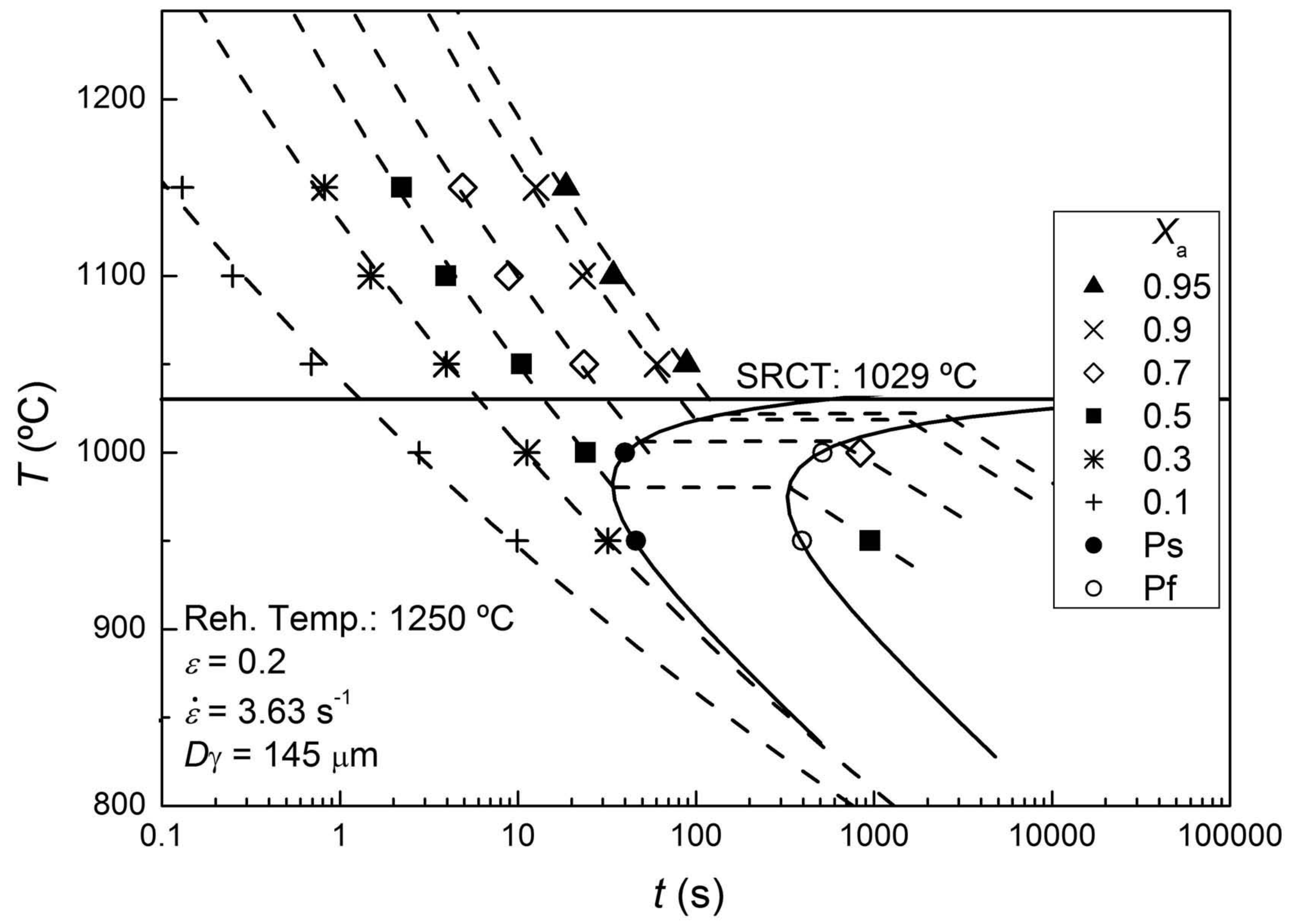




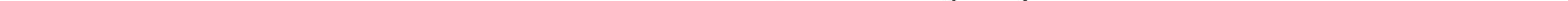




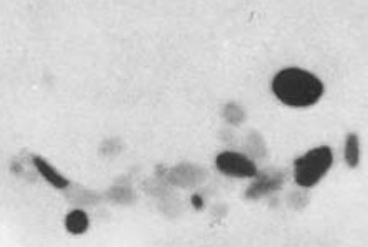

$40 \mathrm{~nm}$

$\longrightarrow$ 


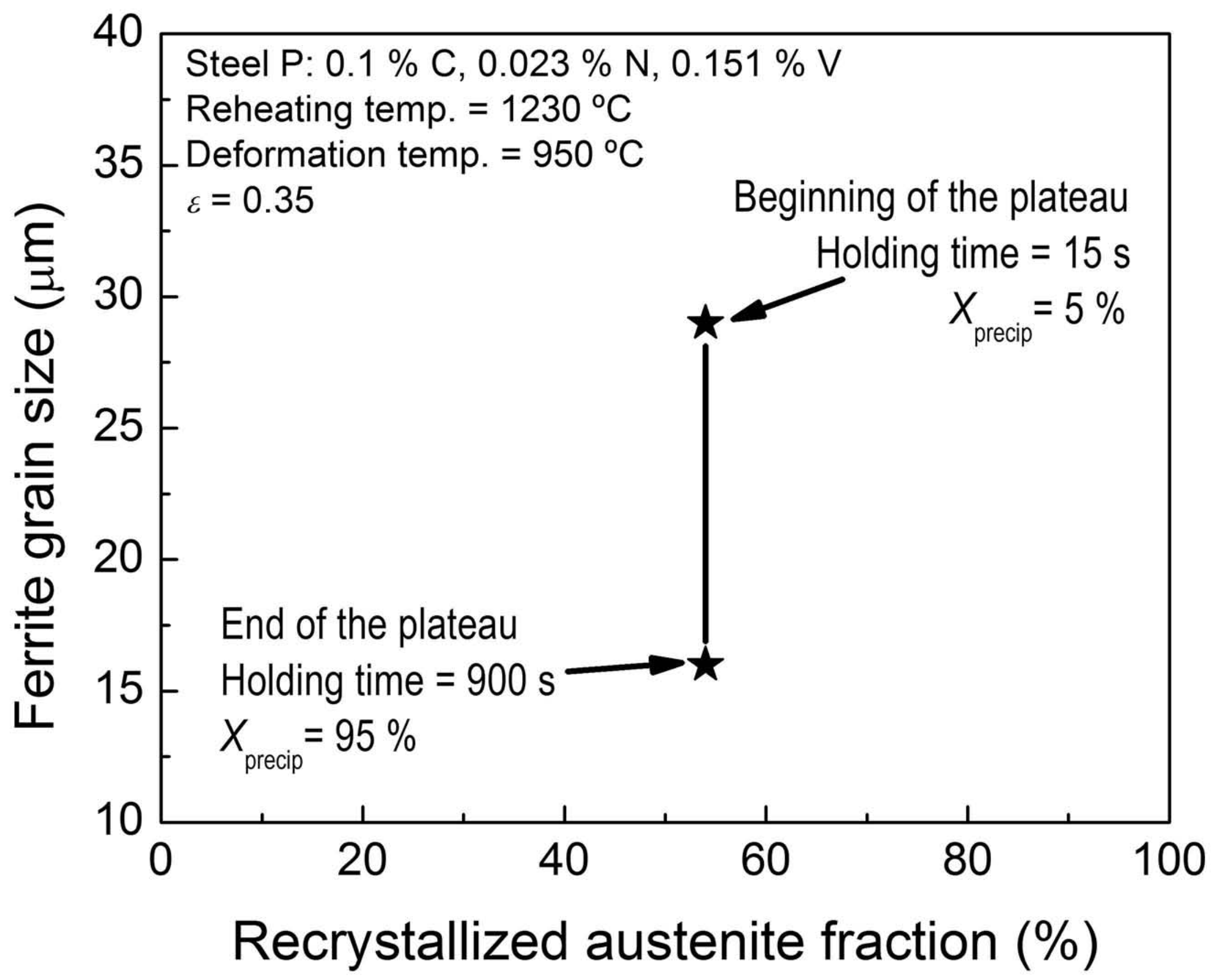




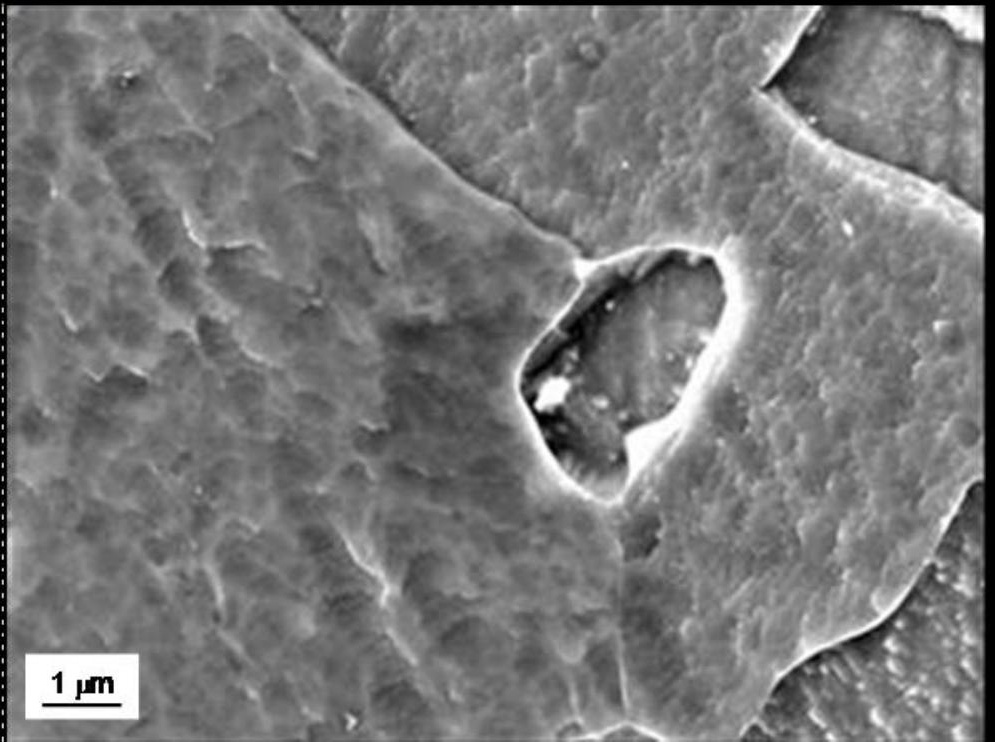




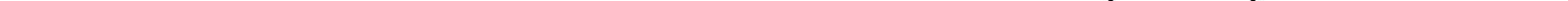

